\title{
Communication
}

\section{Synergistic Effect of Static Compliance and D-dimers to Predict Outcome of Patients with COVID-19-ARDS: A Prospective Multicenter Study}

\author{
Tommaso Tonetti ${ }^{1, *}{ }^{+}$, Giacomo Grasselli ${ }^{2,3}{ }^{\circledR}$, Paola Rucci ${ }^{4}$, Francesco Alessandri ${ }^{5}$, Alessio Dell'Olio ${ }^{1}$, \\ Annalisa Boscolo ${ }^{6}$, Laura Pasin ${ }^{6}\left(\mathbb{D}\right.$, Nicolò Sella ${ }^{6}{ }^{\circledR}$, Chiara Mega $^{1}$, Rita Maria Melotti ${ }^{1}\left(\mathbb{D}\right.$, Massimo Girardis ${ }^{7}$, \\ Stefano Busani ${ }^{7}$, Giacomo Bellani ${ }^{8,9}$, Giuseppe Foti 8,9 , Domenico Luca Grieco ${ }^{10} \oplus$, Vittorio Scaravilli ${ }^{2,3}$, \\ Alessandro Protti ${ }^{11,12}$, Thomas Langer ${ }^{8,13}{ }^{-1}$, Luciana Mascia ${ }^{4}$, Francesco Pugliese ${ }^{5}$, Maurizio Cecconi ${ }^{11,12}$, \\ Roberto Fumagalli ${ }^{8,13}$, Stefano Nava ${ }^{14}$, Massimo Antonelli ${ }^{10}$, Arthur S. Slutsky ${ }^{15}$ (E) Paolo Navalesi ${ }^{6}{ }^{\circ}$, \\ Antonio Pesenti ${ }^{2,3}$ and Vito Marco Ranieri ${ }^{1}$
}

Citation: Tonetti, T.; Grasselli, G.; Rucci, P.; Alessandri, F.; Dell'Olio, A.; Boscolo, A.; Pasin, L.; Sella, N.; Mega, C.; Melotti, R.M.; et al. Synergistic Effect of Static Compliance and D-dimers to Predict Outcome of Patients with COVID-19-ARDS: A Prospective Multicenter Study. Biomedicines 2021, 9, 1228. https:/ / doi.org/10.3390/biomedicines9091228

Academic Editor: Giuseppe Montrucchio

Received: 16 August 2021

Accepted: 9 September 2021

Published: 15 September 2021

Publisher's Note: MDPI stays neutral with regard to jurisdictional claims in published maps and institutional affiliations.

Copyright: (c) 2021 by the authors. Licensee MDPI, Basel, Switzerland. This article is an open access article distributed under the terms and conditions of the Creative Commons Attribution (CC BY) license (https:/ / creativecommons.org/licenses/by/ $4.0 /)$.
1 Dipartimento di Scienze Mediche e Chirurgiche (DIMEC), Anesthesia and Intensive Care Medicine, IRCCS Policlinico di Sant'Orsola, Università di Bologna, 40138 Bologna, Italy; alessio.dellolio@unibo.it (A.D.); chiara-mega@hotmail.com (C.M.); ritamaria.melotti@unibo.it (R.M.M.); m.ranieri@unibo.it (V.M.R.)

2 Fondazione IRCCS Ca'Granda Ospedale Maggiore Policlinico, University of Milan, 20122 Milan, Italy; giacomo.grasselli@unimi.it (G.G.); vittorio.scaravilli@gmail.com (V.S.); antonio.pesenti@unimi.it (A.P.) Department of Pathophysiology and Transplantation, University of Milan, 20122 Milan, Italy

4 Dipartimento di Scienze Biomediche e Neuromotorie (DIBINEM), Alma Mater Studiorum Università di Bologna, 40126 Bologna, Italy; paola.rucci2@unibo.it (P.R.); luciana.mascia@unibo.it (L.M.)

5 Department of Anaesthesia and Intensive Care, Sapienza University of Rome, 00161 Rome, Italy; francescoalessandri1@yahoo.it (F.A.); f.pugliese@uniroma1.it (F.P.)

6 Anesthesia and Critical Care, Department of Medicine-DIMED, University Hospital of Padua, 35127 Padua, Italy; annalisa.boscolo@gmail.com (A.B.); laurapasin1704@gmail.com (L.P.); nico.sella@hotmail.it (N.S.); paolo.navalesi@unipd.it (P.N.)

7 Anesthesia and Critical Care, Policlinico di Modena, Università di Modena e Reggio Emilia, 41125 Modena, Italy; girardis@unimore.it (M.G.); stefano.busani@unimore.it (S.B.)

8 Department of Medicine and Surgery, University of Milano-Bicocca, 20900 Monza, Italy; giacomo.bellani1@unimib.it (G.B.); g.foti@asst-monza.it (G.F.); thomas.langer@unimib.it (T.L.); roberto.fumagalli@ospedaleniguarda.it (R.F.)

9 Department of Anesthesia and Intensive Care Medicine, ASST Monza-Ospedale San Gerardo, 20900 Monza, Italy

10 Department of Anesthesiology and Intensive Care Medicine, Fondazione Policlinico Universitario A. Gemelli IRCCS, 00168 Rome, Italy; dlgrieco@outlook.it (D.L.G.); massimo.antonelli@policlinicogemelli.it (M.A.)

11 Department of Biomedical Sciences, Humanitas University, 20089 Pieve Emanuele, Italy; alessandro.protti@hunimed.eu (A.P.); maurizio.cecconi@hunimed.eu (M.C.)

12 Humanitas Clinical and Research Center-IRCCS, 20089 Rozzano, Italy

13 Dipartimento di Anestesia e Rianimazione Grande Ospedale Metropolitano Niguarda, 20162 Milan, Italy

14 Respiratory and Critical Care Unit, Department of Clinical, Integrated and Experimental Medicine (DIMES), S. Orsola-Malpighi Hospital, Alma Mater University, 40138 Bologna, Italy; stefano.nava@unibo.it

15 Keenan Research Centre for Biomedical Science, St Michael's Hospital, Toronto, ON M5B 1W8, Canada; arthur.slutsky@unityhealth.to

* Correspondence: tommaso.tonetti@unibo.it; Tel.: +39-051-2144348 or +39-051-2143268; Fax: +39-051-6364333

Abstract: The synergic combination of D-dimer (as proxy of thrombotic/vascular injury) and static compliance (as proxy of parenchymal injury) in predicting mortality in COVID-19-ARDS has not been systematically evaluated. The objective is to determine whether the combination of elevated D-dimer and low static compliance can predict mortality in patients with COVID-19-ARDS. A "training sample" (March-June 2020) and a "testing sample" (September 2020-January 2021) of adult patients invasively ventilated for COVID-19-ARDS were collected in nine hospitals. D-dimer and compliance in the first $24 \mathrm{~h}$ were recorded. Study outcome was all-cause mortality at 28-days. Cutoffs for D-dimer and compliance were identified by receiver operating characteristic curve analysis. Mutually exclusive groups were selected using classification tree analysis with chi-square automatic interaction detection. Time to death in the resulting groups was estimated with Cox regression adjusted for SOFA, sex, age, $\mathrm{PaO}_{2} / \mathrm{FiO}_{2}$ ratio, and sample (training/testing). "Training" and "testing" 
samples amounted to 347 and 296 patients, respectively. Three groups were identified: D-dimer $\leq$ $1880 \mathrm{ng} / \mathrm{mL}$ (LD); D-dimer > $1880 \mathrm{ng} / \mathrm{mL}$ and compliance > $41 \mathrm{~mL} / \mathrm{cmH}_{2} \mathrm{O}$ (LD-HC); D-dimer > $1880 \mathrm{ng} / \mathrm{mL}$ and compliance $\leq 41 \mathrm{~mL} / \mathrm{cmH}_{2} \mathrm{O}$ (HD-LC). 28-days mortality progressively increased in the three groups (from $24 \%$ to $35 \%$ and $57 \%$ (training) and from $27 \%$ to $39 \%$ and $60 \%$ (testing), respectively; $p<0.01$ ). Adjusted mortality was significantly higher in HD-LC group compared with $\mathrm{LD}(\mathrm{HR}=0.479, p<0.001)$ and HD-HC $(\mathrm{HR}=0.542, p<0.01)$; no difference was found between LD and HD-HC. In conclusion, combination of high D-dimer and low static compliance identifies a clinical phenotype with high mortality in COVID-19-ARDS.

Keywords: acute respiratory distress syndrome; COVID-19; D-dimer; static compliance; mechanical ventilation

\section{Introduction}

Patients hospitalized for coronavirus disease-2019 (COVID-19) may develop severe hypoxemia requiring Intensive Care Unit (ICU) admission and mechanical ventilation. Acute Respiratory Distress Syndrome (ARDS), the most severe form of hypoxic respiratory failure, occurs in about $15 \%$ to $68 \%$ of hospitalized COVID-19 patients [1], and is characterized by vascular thrombosis [2] and loss of lung aeration [3]. Studies performed in patients with ARDS from other cause than COVID-19 ("classical ARDS") have demonstrated that D-dimers are a proxy of intra-alveolar coagulation and fibrinolysis [4] and static compliance of the respiratory system is a proxy of the size of the ventilable lung ("baby lung") [5].

Extension of vascular thrombosis [6,7] and amount of loss of lung aeration [8,9] has been correlated to clinical outcome of severe COVID-19. Consistently with these data, several studies performed in patients with COVID-19 ARDS showed that (a) concentrations of D-dimers were higher in non-survivors than in survivors [10-15]; (b) lower compliance of the respiratory system in the first day of ventilation was associated with increased risk of 28-day mortality [16]. However, the bulk of these data are not conclusive with respect to the importance of D-dimers and compliance in predicting outcomes in patients with COVID-19 ARDS since (a) most studies were retrospective in nature [10-14]; (b) a synergistic effect of D-dimers and compliance was observed but was not thoroughly analysed; (c) a prognostic model based on D-dimers and compliance was not validated using rigorous statistical techniques based on different samples [17].

The objective of the present study is to prove in two separate samples (a "training sample" and a "testing sample") of patients with COVID-19 ARDS the hypothesis that only the combination of elevated plasmatic D-dimers and reduced respiratory system compliance may predict mortality in patients with COVID-19-ARDS.

\section{Methods}

Data were prospectively collected from nine Italian hospitals (Policlinico di Sant'Orsola (Alma Mater Studiorum, Università di Bologna), Policlinico di Modena (Università di Modena e Reggio Emilia), Ospedale Maggiore Policlinico (Università di Milano), Ospedale Niguarda (Università di Milano-Bicocca, Milan), Ospedale San Gerardo di Monza, (Università di Milano-Bicocca), Istituto Clinico Humanitas (Università Humanitas, Milano), Azienda Ospedaliero-Universitaria (Università di Padova), Policlinico Gemelli (Università Cattolica del Sacro Cuore, Roma), Policlinico Umberto I (Sapienza Università di Roma) Roma). Institutional Review Boards at each hospital approved the study protocol and consent was obtained according to local indications [18]. Patients older than 18 years with confirmed COVID-19 [11] who were admitted to the ICUs were enrolled. Diagnosis of ARDS according to the Berlin definition [19] and invasive mechanical ventilation within $24 \mathrm{~h}$ after admission were the inclusion criteria. A "training sample" during the period March-June 2020 and a "testing sample" during the period September 2020-January 2021 of the pandemic were collected [20]. Study outcome was all-cause mortality at 28-days. The 
first available values of $\mathrm{D}$-dimer and static compliance of the respiratory system during the first $24 \mathrm{~h}$ from study admission were recorded. Static compliance was calculated as previously described [21,22]. End-inspiratory plateau pressure and total positive end-inspiratory pressure were obtained by performing end-inspiratory and end-expiratory occlusions with patients sedated, paralyzed and ventilated in volume-control mode [21,22].

\section{Statistical Methods}

Receiver operating characteristic (ROC) curve analysis was used to identify the optimal cut-off that balanced sensitivity and specificity for D-dimer and static compliance in predicting 28-day mortality [17]. The identified cut-off values of D-dimer and static compliance were then used to perform a classification tree analysis (CTA) with chi-square automatic interaction detection (CHAID) [23-25]. The CTA procedures build decision trees beginning with a root node that includes all cases, then the tree branches into subgroups (or nodes) and grows iteratively. The best discriminating predictor is selected first, and then subsequent predictors are entered into the procedure if they contribute significantly to subtyping cases into homogeneous groups. Variables not useful in discriminating cases do not enter the procedure. The tree grows until a stopping criterion is met or no further significant improvement in the classification of study participants is possible. At the end of the procedure, the study population is partitioned into terminal nodes that are as homogeneous as possible with respect to the categories of the dependent variable [23-25]. The dichotomized D-dimer and static compliance variables were used as input for the CTA procedure. As a rule, the classification tree should be derived in one sample and validated in a separate sample. We chose to use the two different time periods for the derivation (training) and validation (testing) sample.

Cox regression analysis was used to predict time to death at 28-days as a function of the groups resulting from the CTA procedure, using the group with highest mortality as class reference, and adjusting for sequential organ failure assessment (SOFA) score at admission, sex, age, $\mathrm{PaO}_{2} / \mathrm{FiO}_{2}$ ratio $[18,26]$, and sample (training/testing).

Continuous variables were expressed as medians and IQRs. Categorical variables were summarized as absolute and percentage frequencies. Comparison of continuous data between samples was done using Mann-Whitney or Kruskal-Wallis test and comparison of categorical data was done using $\chi^{2}$ or Fisher's exact test. All statistical tests were two sided. The significance level was set at $p<0.05$ and no imputation of missing data was performed. Analyses were done using IBM SPSS (IBM Corp. Released 2019. IBM SPSS Statistics for Windows, Version 26.0. IBM Corp., Armonk, NY, USA).

\section{Results}

Seven-hundred and thirty patients were screened. Eighty-seven patients were excluded (36 because they did not match ARDS criteria, and 51 for missing values of D-dimers and static compliance on admission). Of the remaining 643 patients, 347 were admitted from March-June 2020 ("training sample") and 296 from September 2020-January 2021 ("testing sample").

In the overall study cohort (643 patients), median time from hospital admission to intubation was 3 days (IQR 1-5). Median age was 64 years (56-71), 530 (77.4\%) were males, and all were ventilated according to a conventional protective ventilatory strategy [21]. Median static compliance was $41 \mathrm{~mL} / \mathrm{cmH}_{2} \mathrm{O}$ (33-52) and median D-dimer concentration was $1560 \mathrm{ng} / \mathrm{mL}$ (704-4900). Table 1 shows baseline characteristics of the "training" and "testing" samples. Small but significant difference in SOFA score at admission, $\mathrm{PaO}_{2} / \mathrm{FiO}_{2}$, static compliance, and ventilator settings were observed. The 28 -day mortality was $36.8 \%$ (143 of 389 patients) in the training sample, and 37.2\% (110 of 296) in the testing sample $\left(\chi^{2}=0.012, p=0.914\right)$. 
Table 1. Demographic, ventilatory and laboratory variables collected within $24 \mathrm{~h}$ of ICU admission in COVID-19-ARDS patients.

\begin{tabular}{|c|c|c|c|}
\hline & Training Sample & Testing Sample & $p$-Value \\
\hline Male gender $(n(\%))$ & $302(77.6)$ & $228(77.0)$ & 0.8506 \\
\hline Age (years) & $64(56-70)$ & $65(57-71)$ & 0.3228 \\
\hline $\begin{array}{l}\text { Time from hospital admission to } \\
\text { invasive mechanical ventilation } \\
\text { (days) }\end{array}$ & $2(1-5)$ & $3(1-7)$ & 0.1117 \\
\hline SOFA score at ICU admission & $4(4-6)$ & $4(3-5)$ & $<0.0001$ \\
\hline Weight (kg) & $85(75-92)$ & 85 (75-95) & 0.6206 \\
\hline Height (cm) & $171(168-178)$ & $170(165-178)$ & 0.5421 \\
\hline $\operatorname{BMI}\left(\mathrm{kg} / \mathrm{m}^{2}\right)$ & $27.8(25.6-31.1)$ & $27.8(26.0-31.3)$ & 0.2610 \\
\hline PBW (kg) & $66(62-73)$ & $66(61-73)$ & 0.5473 \\
\hline Respiratory rate (bpm) & $20(16-24)$ & $19(16-22)$ & 0.1704 \\
\hline $\mathrm{P} / \mathrm{F}$ ratio $(\mathrm{mmHg})$ & $132(94-176)$ & $114(86-150)$ & 0.0003 \\
\hline $\operatorname{PEEP}\left(\mathrm{cmH}_{2} \mathrm{O}\right)$ & $12(10-14)$ & $10(10-12)$ & $<0.0001$ \\
\hline Tidal volume (mL) & $480(420-530)$ & $450(400-500)$ & 0.0001 \\
\hline $\mathrm{TV} / \mathrm{PBW}(\mathrm{mL} / \mathrm{kg})$ & $7.1(6.4-8.1)$ & $6.8(6.3-7.6)$ & 0.0077 \\
\hline Plateau pressure $\left(\mathrm{cmH}_{2} \mathrm{O}\right)$ & $24(22-27)$ & $23(21-25)$ & $<0.0001$ \\
\hline $\begin{array}{l}\text { Static compliance of the } \\
\text { respiratory system }\left(\mathrm{mL} / \mathrm{cmH}_{2} \mathrm{O}\right)\end{array}$ & $42(34-53)$ & $40(31-49)$ & 0.0041 \\
\hline $\mathrm{pH}$ (units) & $7.39(7.33-7.43)$ & $7.38(7.33-7.44)$ & 0.7407 \\
\hline $\mathrm{PaO}_{2}(\mathrm{mmHg})$ & $82(70-104)$ & $85(72-107)$ & 0.0581 \\
\hline $\mathrm{PaCO}_{2}(\mathrm{mmHg})$ & $46(39-53)$ & $44(38-51)$ & 0.2559 \\
\hline D-dimer (ng/mL) & $1620(714-5111)$ & $1510(669-4685)$ & 0.5209 \\
\hline Glucocorticoids $(n(\%))$ & $145 / 336(43.2)$ & $243 / 296(82.1)$ & $<0.0001$ \\
\hline Full-dose anticoagulation $(n(\%))$ & $213 / 317(67.2)$ & 244/291 (83.8) & $<0.0001$ \\
\hline Remdesivir $(n(\%))$ & $66 / 270(24.4)$ & $34 / 296(11.5)$ & 0.0001 \\
\hline Tocilizumab $(n(\%))$ & $67 / 274(24.5)$ & $0 / 296(0.0)$ & $<0.0001$ \\
\hline Hydroxychloroquine $(n(\%))$ & $293 / 305(96.1)$ & $0 / 296(0.0)$ & $<0.0001$ \\
\hline
\end{tabular}

Continuous variables are presented as median (1st-3rd quartile); categorical variables are expressed as absolute number (percentage). Abbreviations: $\mathrm{BMI}$, body mass index; $\mathrm{PBW}$, predicted body weight; $\mathrm{P} / \mathrm{F}$ ratio, $\mathrm{PaO}_{2} / \mathrm{FiO}_{2}$ ratio; $\mathrm{PEEP}$, positive end-expiratory pressure; TV, tidal volume; $\mathrm{PaO}_{2}$, arterial partial pressure of oxygen; $\mathrm{PaCO}_{2}$, arterial partial pressure of carbon dioxide.

The areas under the ROC curves in all 643 patients for D-dimers and static compliance were both significantly larger than that of an arbitrary test without a discriminatory value $(\mathrm{AUC}=0.657 ; 95 \%$ CI $0.614-0.700$ and $\mathrm{AUC}=0.580 ; 95 \%$ CI $0.533-0.628$, respectively) (Figure 1). The cut-off values for D-dimers and static compliance that balanced sensitivity and specificity were $1880 \mathrm{ng} / \mathrm{mL}$ (sensitivity $61.9 \%$; specificity $63.6 \%$ ) and $41 \mathrm{~mL} / \mathrm{cmH}_{2} \mathrm{O}$ (sensitivity $58.0 \%$; specificity $56.6 \%$ ). 

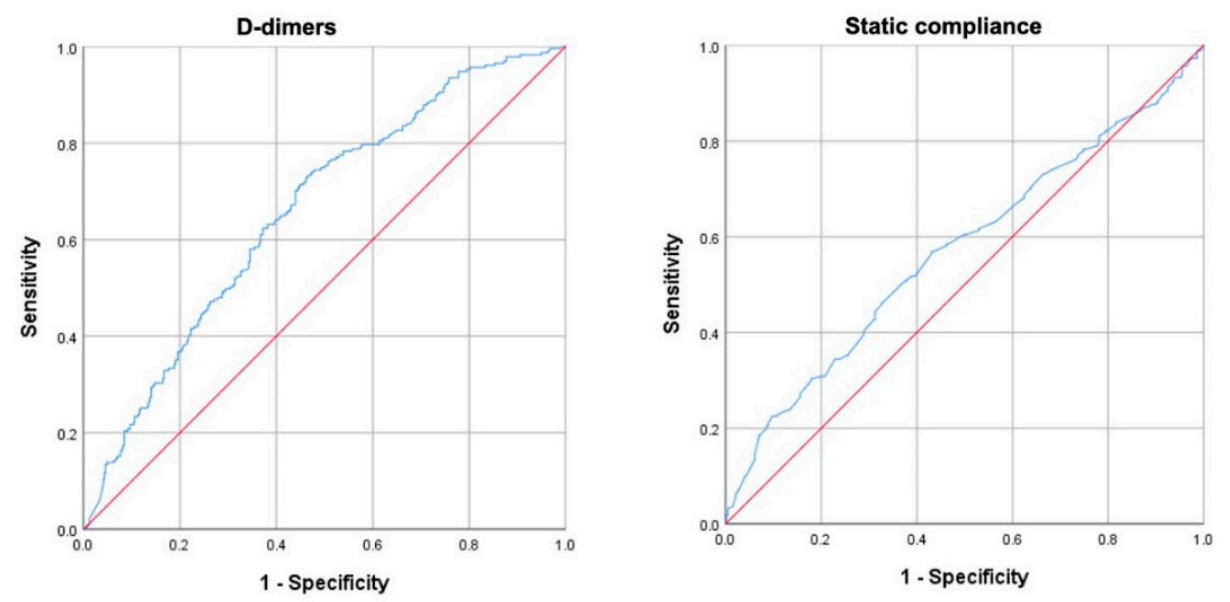

Figure 1. ROC curves for D-dimers (left panel) and compliance of the respiratory system (right panel). The actual ROC curves are blue, while the red line represents an arbitrary (theoretical) test that is expected a priori to have no discriminatory value.

Classification tree analysis partitioned the study population into three mutually exclusive groups: patients with D-dimer $\leq 1880 \mathrm{ng} / \mathrm{mL}$ (LD); patients with D-dimer $>1880 \mathrm{ng} / \mathrm{mL}$ and static compliance $>41 \mathrm{~mL} / \mathrm{cmH}_{2} \mathrm{O}$ (HD-HC); patients with D-dimer $>1880 \mathrm{ng} / \mathrm{mL}$ and compliance $\leq 41 \mathrm{~mL} / \mathrm{cmH}_{2} \mathrm{O}$ (HD-LC). The probability of death at 28 -days progressively increased, from $24 \%$ to $35 \%$ and to $57 \%$ in the training sample and from $27 \%$ to $39 \%$ and $60 \%$ in the testing sample, respectively $\left(\chi^{2}=17.901, p<0.001\right.$ at the first partition and $\chi^{2}=8.283, p=0.004$ at the second partition) (Figure 2).
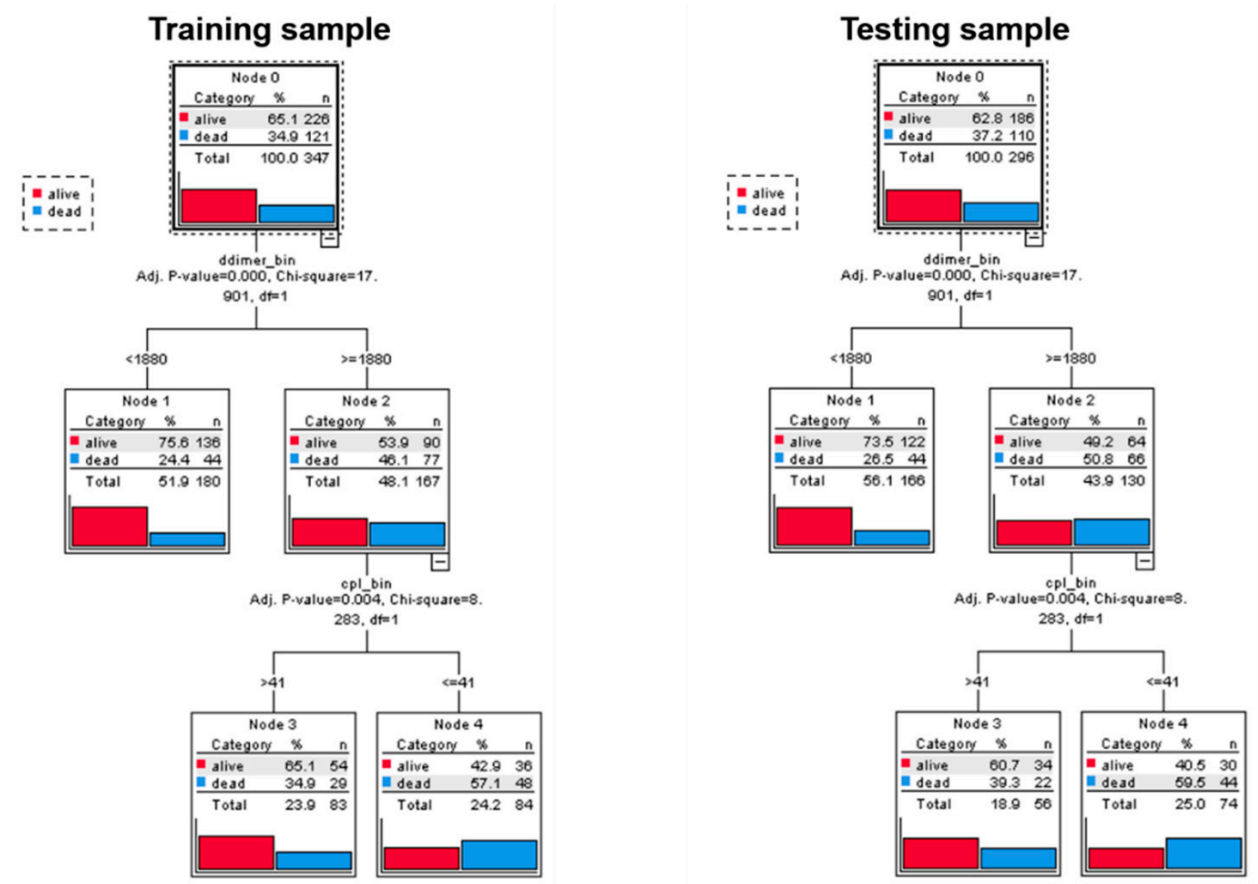

Figure 2. Classification tree results in the training $(\mathrm{N}=347)$ and in the testing $(\mathrm{N}=296)$ sample. Both trees have three final nodes.

Cox regression analysis demonstrated that mortality, adjusted for covariates (age: $\mathrm{HR}=1.075,95 \%$ CI 1.058-1.092, $p$ < 0.001; SOFA: $\mathrm{HR}=1.084,95 \%$ CI 1.015-1.158; $\mathrm{PaO}_{2} / \mathrm{FiO}_{2}$ ratio: $\mathrm{HR}=0.995,95 \%$ CI 0.993-0.998), was significantly higher in the HD-LC group compared with the LD $(\mathrm{HR}=0.479,95 \%$ CI $0.356-0.647, p<0.001)$ and the HD-HC $(\mathrm{HR}=0.542$, 
95\% CI 0.380-0.772, $p<0.01)$; no difference in mortality was found between LD and HD-HC (Table 2 and Figure 3).

Table 2. Results of Cox proportional risk analysis for mortality. Class reference is HD-LC.

\begin{tabular}{ccc}
\hline Factor & & Hazard Ratio (95\% CI) \\
\hline \multirow{2}{*}{ Class } & LD & $0.479(0.356-0.647)$ \\
\cline { 2 - 3 } & HD-HC & $0.542(0.380-0.772)$ \\
\cline { 2 - 3 } & HD-LC & 1.000 (reference) \\
\hline Age & & $1.075(1.058-1.092)$ \\
\hline SOFA score & & $1.084(1.015-1.158)$ \\
\hline P/F ratio & & $0.995(0.993-0.998)$ \\
\hline
\end{tabular}

HD-LC: High D-dimers-Low Compliance; HD-HC: High D-dimers-High Compliance; LD: Low D-dimers; P/F: arterial to inspiratory oxygen; SOFA score: Sequential Organ Failure Assessment (SOFA) Score.

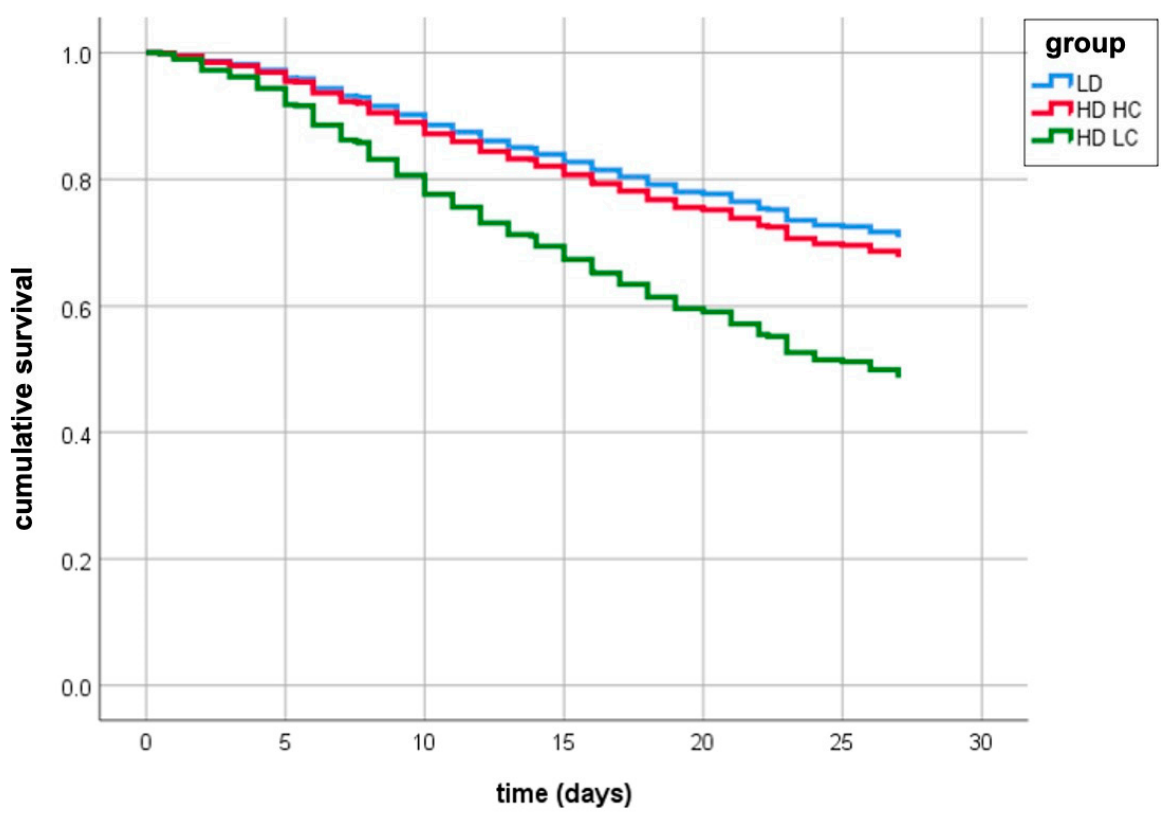

Figure 3. Survival estimates of patients with low D-dimer (LD), high-D-dimer and low compliance (HD-LC), high-D-dimer and high compliance (HD-HC) from Cox regression analysis, adjusted for age, gender, $\mathrm{SOFA}, \mathrm{PaO}_{2} / \mathrm{FiO}_{2}$ ratio, and sample (testing vs. training).

\section{Discussion}

The present study shows that in patients with COVID-19-ARDS combination of baseline plasma concentrations of D-dimer higher than $1880 \mathrm{ng} / \mathrm{mL}$ and of baseline values of respiratory system compliance lower than $41 \mathrm{~mL} / \mathrm{cmH}_{2} \mathrm{O}$ are associated with a significantly increased risk of death at 28-days, compared to patients presenting with alterations in only one of each parameter.

Mortality rate of hospitalized COVID-19 patients ranges between 13\% and 89\% [1] with an associated relative risk of death of 7.99 (95\% CI: 4.9 to 13) [27]. Pathophysiology of COVID-19 ARDS is characterized by loss of lung aeration with large consolidated, nonaerated regions and ground-glass opacities [28] and by platelet-fibrin microthrombi at the alveolar-capillary barrier [29-31]. Since proportion of compromised lung volume [3,8] and abnormal coagulation parameters [7] have been associated with outcome, several studies have investigated the role of static compliance [9,16,18], and D-dimers [32] to predict outcome. This is based on several studies performed in "classical ARDS" that have demonstrated that static compliance is a reasonable proxy of the size of the normally 
aerated lung (baby lung) [5] and that D-dimers are a marker of thromboembolic disorders and extravascular fibrin deposition [4].

Early descriptions of COVID-19 demonstrated that increased concentrations of Ddimers were associated with worse clinical outcome [10-15]. A cohort study including 2377 adults hospitalized with COVID-19 in a large New York City hospital network, showed that patients presenting with elevated baseline concentration of D-dimer within "normal" ranges were less likely to have critical illness (odds ratio 2.4) [32]. A multi-center cohort study collected data by chart review of 3418 ICU patients and showed that more than $93 \%$ of patients had D-dimers values above the upper normality limit and an almost two-fold increased odds of death was observed in the patients with D-dimer levels higher than $\sim 4000 \mathrm{ng} / \mathrm{mL}$ [33]. A systematic review of more than 2700 patients with COVID-19 showed that patients with increased D-dimers had an odds ratio greater than 5 for developing severe disease [34]. Three retrospective studies on COVID-19 hospitalized patients provide ROC analysis on 248, 343 and 1065 consecutive COVID-19 cases, respectively. Plasma D-dimer concentrations $>2140 \mathrm{ng} / \mathrm{mL},>2000 \mathrm{ng} / \mathrm{mL}$ and $>2380 \mathrm{ng} / \mathrm{mL}$ at admission were respectively identified as the optimal cut-offs for discriminating survivors from non-survivors (AUC $=0.85,0.89$ and 0.69 , respectively) with sensitivities of $88.2 \%, 92.3 \%$ and $51 \%$, respectively; specificities were $71.3 \%, 83.3 \%$ and $78 \%$, respectively [35-37].

Data regarding the association between static compliance and outcome in patients with COVID-19 ARDS are less consistent. Botta et al. in a retrospective study of 553 patients found that lower static compliance on the first day of ventilation was associated with increased risk of death at 28-day (OR 0.75 (95\% CI 0.57-0.98), $p=0.037$ ) [16]. The French REVA network found a small but significant difference in static compliance between survivors and non-survivors ((34 (27-43) vs. $\left.\left.32(24-41) \mathrm{mL} / \mathrm{cmH}_{2} \mathrm{O} ; p<0.001\right)\right)$ [38]. On the contrary, Vandenbunder et al. in a prospective study including 372 patients found that static compliance on the first day of ventilation was not related with 28-day survival [9]. Moreover, a sensitivity analysis of 742 patients with COVID-ARDS showed that ICU discharge and risk of death at 28-days were not influenced by static compliance [39]. Grasselli et al. examined the relationship of baseline D-dimer and static compliance with mortality. In 301 patients with COVID-19-ARDS, patients with static compliance less than/equal to the observed median $\left(41 \mathrm{~mL} / \mathrm{cmH}_{2} \mathrm{O}\right)$ and D-dimer concentrations greater than the median $(1880 \mathrm{ng} / \mathrm{mL})$ had markedly increased 28 -day mortality compared with other patients [18]. Interestingly, the cut-off values identified by ROC curves in the present study very similar to the median values of the study by Grasselli et al. [18]; this may be due to the fact that all patients from that study are included in the "training set" of the present study. Although the present study may appear in some ways similar to the previous study from our group, we believe the present study conveys a more methodologically robust message and allows for more definitive conclusions on the role of D-dimers and static compliance in the pathophysiology and outcome of COVID-19-ARDS patients.

However, the bulk of these studies remain inconclusive regarding the impact of Ddimers and static compliance in predicting outcome in patients with COVID-19 ARDS because of the retrospective nature of most studies and because they did not use rigorous statistical techniques to evaluate the predictive ability of these variables in independent samples [10-14,18].

The major strength of the present study is the use of robust statistical methods to identify threshold values of D-dimer $(1880 \mathrm{ng} / \mathrm{mL})$ and static compliance $\left(41 \mathrm{~mL} / \mathrm{cmH}_{2} \mathrm{O}\right)$ associated with the risk of death with optimal sensitivity and specificity through ROC analysis. We used these cut-off values to stratify patients into subgroups with different mortality risk through classification tree analysis and validated this tree in an independent sample. Specifically, classification tree analysis generated three mutually exclusive groups: patients with D-dimer $\leq 1880 \mathrm{ng} / \mathrm{mL}$ (LD); patients with D-dimer $>1880 \mathrm{ng} / \mathrm{mL}$ and static compliance $>41 \mathrm{~mL} / \mathrm{cmH}_{2} \mathrm{O}$ (HD-HC); patients with D-dimer $>1880 \mathrm{ng} / \mathrm{mL}$ and static compliance $\leq 41 \mathrm{~mL} / \mathrm{cmH}_{2} \mathrm{O}$ (HD-LC). Probability of death at 28-days progressively increased in these three groups in both the training and testing datasets. Interestingly, 
static compliance did not contribute significantly to subtyping patients with low D-dimers and was therefore excluded from the respective branch. Lastly, Cox regression analysis showed that, after adjusting for covariates (age, SOFA, and $\mathrm{PaO}_{2} / \mathrm{FiO}_{2}$ ratio), mortality was significantly higher in the HD-LC group compared with the LD and the HD-HC; no difference in outcome was observed between LD and HD-HC (Table 2 and Figure 3).

This study has several limitations. First, it should be acknowledged that other laboratory parameters (e.g., LDH, lymphocytes, creatinine, C-reactive protein) have been associated with severity and mortality of COVID-19 [40-42]. However, since we aimed to identify predictors of outcome in COVID-19-ARDS (and not in COVID-19), we chose to focus on D-dimers and static compliance based on the preliminary observation that only the combination of increased D-dimers and low static compliance (rather than high D-dimers only vs. low compliance only) identifies a specific phenotype of COVID-19ARDS patients characterized by very high mortality [18]. Second, although D-dimers are considered a sensitive biomarker for thromboembolic disorders and extravascular fibrin deposition [4,43], and previous studies suggested that high concentration of D-dimer in the broncho-alveolar lavage of patients with classic ARDS reflect thrombotic activity and fibrin degradation [44], several studies have shown that D-dimers are not specific since other conditions such as pregnancy, renal failure, sepsis are associated with raised D-dimer levels, and that plasma D-dimer levels can be caused by lysis of extra-vascular rather than intra-vascular fibrin [45-47]. Moreover, the relatively "small" areas under the ROC curves (0.657; 95\% CI 0.614-0.700 for D-dimers, and 0.580; 95\% CI 0.533-0.628, for static compliance) is another potential limitation of the study; further, AUC for D-dimers is lower than in two previous studies [35,36], but very similar to another, bigger, retrospective study [37] and this could be due, at least in part, to the intrinsic heterogeneity of consecutive ICU patients. However, classification tree analysis may overcome these limitations since ROC analysis was implemented to objectively identify cut-off values that were validated by the classification tree analysis with chi-square automatic interaction detection [23-25]. Finally, although low values of static compliance largely reflect the degree of lung volume loss [5], when evaluated by the Berlin definition as criterion for severity of ARDS, compliance was not able to identify a group of patients with higher mortality [19].

In conclusion, the present study demonstrates that, in mechanically ventilated patients with COVID-19-ARDS, only the combination D-dimer values higher than $1880 \mathrm{ng} / \mathrm{mL}$ and compliance of the respiratory system less than $41 \mathrm{~mL} / \mathrm{cmH}_{2} \mathrm{O}$ allow patient stratification into subgroups at increased risk of death, and identify a clinical phenotype with extremely high mortality that may benefit from more aggressive treatment and may be included in future trials based on enrichment strategies.

Author Contributions: Conceptualization, T.T., G.G., P.R., A.D., L.M., S.N., A.S.S., A.P. (Antonio Pesenti) and V.M.R.; Formal analysis, P.R.; Investigation, T.T., G.G., F.A., A.D., A.B., L.P., N.S., C.M., R.M.M., M.G., S.B., G.B., G.F., D.L.G., V.S., T.L., A.P. (Alessandro Protti), L.M., F.P., M.C., R.F., M.A., P.N., A.P. (Antonio Pesenti) and V.M.R.; Methodology, T.T., P.R., A.S.S. and V.M.R.; Supervision, T.T., G.G., S.N., A.S.S., A.P. (Antonio Pesenti) and V.M.R.; Writing—original draft, T.T., G.G., P.R., A.D., L.M., S.N., A.S.S., A.P. (Antonio Pesenti) and V.M.R.; Writing-review \& editing, T.T., G.G., P.R., F.A., A.D., A.B., L.P., N.S., C.M., R.M.M., M.G., S.B., G.B., G.F., D.L.G., V.S., T.L., A.P. (Alessandro Protti), L.M., F.P., M.C., R.F., S.N., M.A., A.S.S., P.N. and A.P. (Antonio Pesenti). All authors have read and agreed to the published version of the manuscript.

Funding: This research received no external funding.

Institutional Review Board Statement: The study was conducted according to the guidelines of the Declaration of Helsinki, and approved by the following Ethics Committees: Comitato Etico Milano Area 2 (Approval Code: 236_2020, date: 2 March 2020); Comitato Etico Area Vasta Emilia CentroBologna (Approval Code: 282/2020/Oss/AOUBo, date: 24 March 2020), Comitato Etico dell'Azienda Ospedale Università di Padova (Approval Code: 4853/AO/20, date: 2 April 2020), Comitato Etico dell'Azienda Policlinico Umberto I-Roma (Approval Code: 109/2020, date: 3 April 2020). 
Informed Consent Statement: Consent was obtained or waived according to local ethics committees indications.

Data Availability Statement: De-identified individual participant data that underlie results reported in this article will be available. Applicant must provide: (1) a methodologically sound approach to achieve scientific aims; (2) formal documents of Ethics Committee approval of applicant's institution. Data will be made available pending authorization of the Policlinico di Sant'Orsola Ethics Committee that will review applicant's request and after signing an appropriate data sharing agreement. Proposals should be directed to m.ranieri@unibo.it. Data will be available following publication; no end date.

Acknowledgments: List of Collaborators (affiliations in parenthesis): Alberto Zanella, Alfredo Lissoni, Nicola Rossi, Amedeo Guzzardella, and Luigi Vivona (Fondazione IRCCS Ca' Granda Ospedale Maggiore Policlinico, University of Milan, Milan, Italy); Francesca Dalla Corte (Humanitas Clinical and Research Center-IRCCS—Rozzano (MI)—Italy); Daniel Zambelli (Humanitas University, Department of Biomedical Sciences_Pieve Emanuele (MI)-Italy); Gennaro de Pascale (Department of Anesthesiology and Intensive Care Medicine, Fondazione Policlinico Universitario A. Gemelli IRCCS, Rome, Italy); Giacinto Pizzilli, Alessio Dell'olio (Policlinico Sant'Orsola Malpighi, Bologna, Italy); Irene Coloretti, Emanuela Biagioni (Anesthesia and Critical Care, Policlinico di Modena, Università di Modena e Reggio Emilia, Modena, Italy), Laura di Sano (Department of Anaesthesia and Intensive Care, Sapienza University of Rome, Rome, Italy), Chiara Pretto; Martina Tocco; Enrico Tamburini; Ilaria Valeri; Giulio Andreatta; Leonardo Gandolfi; Alessandra Gadaldi; Nicolò Brumana; Edoardo Forin; Christelle Correale; Davide Fregolent; Pier Francesco Pirelli; Davide Marchesin; Matteo Perona; Nicola Franchetti; Michele Della Paolera; Caterina Simoni; Tatiana Falcioni; Alessandra Tresin; Chiara Schiavolin; Aldo Schiavi; Sonila Vathi; Daria Sartori; Alice Sorgato; Elisa Pistollato; Federico Linassi; Eugenio Serra; Demetrio Pittarello; Tommaso Pettenuzzo; Alessandro De Cassai; Elisa Michieletto; Luisa Muraro; Arianna Peralta; Paolo Persona; Enrico Petranzan; Francesco Zarantonello; Alessandro Graziano; Eleonora Piasentini (U.O.C. Istituto di Anestesia e Rianimazione, Azienda Ospedale Università di Padova); Ivo Tiberio; Ottavia Bond (U.O.C. Anestesia e Rianimazione, Azienda Ospedale Università di Padova); Lorenzo Bernardi; Roberto Pianon (U.O.C. Anestesia e Rianimazione, Presidio Ospedaliero San Martino, Belluno (BL), AULSS 1 Dolomiti); Flavio Badii (U.O.C. Anestesia e Rianimazione, Ospedale di Vittorio Veneto, Vittorio Veneto (TV), AULSS 2 Marca Trevigiana); Enrico Bosco (U.O.C. Anestesia e Rianimazione, Ospedale di Conegliano, Conegliano (TV), AULSS 2 Marca Trevigiana); Moreno Agostini (U.O.C. Anestesia e Rianimazione, Ospedale di Montebelluna, Montebelluna (TV), AULSS 2 Marca Trevigiana); Antonio Farnia; Mario Peta (U.O.C. Anestesia e Rianimazione, Ospedale Ca' Foncello, Treviso, AULSS 2 Marca Trevigiana); Mauro Antonio Calò (U.O.C. Anestesia, Rianimazione e Terapia Antalgica, Presidio Ospedaliero di Mirano, Mirano (VE) AULSS 3 Serenissima); Marco Meggiolaro (U.O.C. Anestesia e Rianimazione, Ospedale SS. Giovanni e Paolo, Venezia, AULSS 3 Serenissima); Francesco Lazzari; Ivan Martinello; Giorgio Fullin; Francesco Papaccio (U.O.C. Anestesia e Rianimazione, Ospedale dell'Angelo, Mestre (VE), AULSS 3 Serenissima); Alfeo Bonato; Camilla Sgarabotto (U.O.C. Anestesia e Rianimazione, Ospedale di Cittadella, Cittadella, AULSS 6 Euganea); Fabio Baratto MD; Francesco Montacciani; Parnigotto Alessandra (U.O.C. Anestesia e Rianimazione, Ospedali Riuniti Padova Sud, Monselice, AULSS 6 Euganea); Giuseppe Gagliardi; Gioconda Ferraro (U.O.C. Anestesia e Rianimazione, Ospedali di Rovigo e Trecenta, Rovigo, AULSS 5 Polesana); Luigi Ongaro (U.O.C. Anestesia e Rianimazione, Ospedale Alto Vicentino, Santorso (VI), AULSS 7 Pedemontana); Marco Baiocchi (U.O.C. Anestesia e Rianimazione, Ospedale San Bassiano, Bassano del Grappa (VI), AULSS 7 Pedemontana); Vinicio Danzi; Silvia De Rosa (U.O.C Anestesia e Rianimazione, Ospedale di Vicenza, Vicenza (VI), AULSS 8 Berica); Enrico Polati; Katia Donadello; Leonardo Gottin (U.O.C. Anestesia e Rianimazione B, Azienda Ospedaliera Universitaria Integrata Verona, Verona (VR)); Paolo Zanatta (U.O.C. Anestesia e Rianimazione A, Azienda Ospedaliera Universitaria Integrata Verona, Verona (VR)); Simonetta Marchiotto; Silvia Bassanini (U.O.C Anestesia e Rianimazione, Ospedale Magalini di Villafranca, Legnago (VR), AULSS 9 Scaligera); Massimo Zamperini; Ivan Daroui (Dipartimento di Anestesia, Rianimazione e Terapia Antalgica, IRCCS Sacro Cuore-Don Calabria, Negrar (VR)); Fabio Toffoletto (U.O.C. Anestesia e Rianimazione, Ospedali di San Donà di Piave e Jesolo, San Donà di Piave (VE), AULSS 4 Veneto Orientale); Paolo Rosi (Emergency Medical Services, Regional Department, AULSS 3, Venice, Italy). 
Conflicts of Interest: GG reports personal fees and non-financial support from Getinge, personal fees and non-financial support from Biotest, personal fees from Thermofisher, grants and personal fees from Fisher\&Paykel, personal fees from Draeger Medical, outside the submitted work; MC reports personal fees from Edwards Lifesciences, personal fees from Directed Systems, personal fees from Cheetah Medical, outside the submitted work; ASS reports personal fees from Baxter, and Novalung/Xenios; APe reports personal fees from Maquet, personal fees from Novalung/Xenios, personal fees from Baxter, personal fees from Boehringer Ingelheim, outside the submitted work. All other authors report no conflict of interest.

\section{References}

1. Tzotzos, S.J.; Fischer, B.; Fischer, H.; Zeitlinger, M. Incidence of ARDS and outcomes in hospitalized patients with COVID-19: A global literature survey. Crit. Care 2020, 24, 516. [CrossRef]

2. Ackermann, M.; Verleden, S.E.; Kuehnel, M.; Haverich, A.; Welte, T.; Laenger, F.; Vanstapel, A.; Werlein, C.; Stark, H.; Tzankov, A.; et al. Pulmonary Vascular Endothelialitis, Thrombosis, and Angiogenesis in Covid-19. N. Engl. J. Med. 2020, 383, 120-128. [CrossRef] [PubMed]

3. Lanza, E.; Lanza, E.; Muglia, R.; Bolengo, I.; Santonocito, O.G.; Lisi, C.; Angelotti, G.; Morandini, P.; Savevski, V.; Politi, L.S.; et al. Quantitative chest CT analysis in COVID-19 to predict the need for oxygenation support and intubation. Eur. Radiol. 2020, 30, 6770-6778. [CrossRef] [PubMed]

4. Fuchs-Buder, T.; de Moerloose, P.; Ricou, B.; Reber, G.; Vifian, C.; Nicod, L.; Romand, J.; Suter, P. Time course of procoagulant activity and D dimer in bronchoalveolar fluid of patients at risk for or with acute respiratory distress syndrome. Am. J. Respir. Crit. Care Med. 1996, 153, 163-167. [CrossRef] [PubMed]

5. Gattinoni, L.; Pesenti, A. The concept of "baby lung". Intensive Care Med. 2005, 31, 776-784. [CrossRef]

6. Sriram, K.; Insel, P.A. Inflammation and thrombosis in COVID-19 pathophysiology: Proteinase-activated and purinergic receptors as drivers and candidate therapeutic targets. Physiol. Rev. 2021, 101, 545-567. [CrossRef] [PubMed]

7. McFadyen, J.D.; Stevens, H.; Peter, K. The Emerging Threat of (Micro)Thrombosis in COVID-19 and Its Therapeutic Implications. Circ. Res. 2020, 127, 571-587. [CrossRef] [PubMed]

8. Colombi, D.; Bodini, F.C.; Petrini, M.; Maffi, G.; Morelli, N.; Milanese, G.; Silva, M.; Sverzellati, N.; Michieletti, E. Well-aerated Lung on Admitting Chest CT to Predict Adverse Outcome in COVID-19 Pneumonia. Radiology 2020, 296, E86-E96. [CrossRef]

9. Boscolo, A.; Sella, N.; Lorenzoni, G.; Pettenuzzo, T.; Pasin, L.; Pretto, C.; Tocco, M.; Tamburini, E.; de Cassai, A.; Rosi, P.; et al. Static compliance of the respiratory system in COVID-19 related ARDS: An international multicenter study. Crit. Care 2021, 25, 52.

10. Cao, B.; Chen, H.; Zhou, F.; Yu, T.; Du, R.; Fan, G.; Liu, Y.; Liu, Z.; Xiang, J.; Wang, Y.; et al. Clinical course and risk factors for mortality of adult inpatients with COVID-19 in Wuhan, China: A retrospective cohort study. Lancet 2020, 395, 1054-1062.

11. Chen, T.; Wu, D.; Chen, H.; Yan, W.; Yang, D.; Chen, G.; Ma, K.; Xu, D.; Yu, H.; Wang, H.; et al. Clinical characteristics of 113 deceased patients with coronavirus disease 2019: Retrospective study. BMJ 2020, 368, m1091. [CrossRef] [PubMed]

12. Wang, D.; Hu, B.; Hu, C.; Zhu, F.; Liu, X.; Zhang, J.; Wang, B.; Xiang, H.; Cheng, Z.; Xiong, Y.; et al. Clinical Characteristics of 138 Hospitalized Patients with 2019 Novel Coronavirus-Infected Pneumonia in Wuhan, China. JAMA 2020, 323, 1061. [CrossRef]

13. Wu, C.; Chen, X.; Cai, Y.; Xia, J.; Zhou, X.; Xu, S.; Huang, H.; Zhang, L.; Zhou, X.; Du, C.; et al. Risk Factors Associated with Acute Respiratory Distress Syndrome and Death in Patients with Coronavirus Disease 2019 Pneumonia in Wuhan, China. JAMA Intern. Med. 2020, 180, 934. [CrossRef] [PubMed]

14. Tang, N.; Li, D.; Wang, X.; Sun, Z. Abnormal coagulation parameters are associated with poor prognosis in patients with novel coronavirus pneumonia. J. Thromb. Haemost. 2020, 18, 844-847. [CrossRef]

15. Huang, C.; Wang, Y.; Li, X.; Ren, L.; Zhao, J.; Hu, Y.; Zhang, L.; Fan, G.; Xu, J.; Gu, X.; et al. Clinical features of patients infected with 2019 novel coronavirus in Wuhan, China. Lancet 2020, 395, 497-506. [CrossRef]

16. Botta, M.; Tsonas, A.M.; Pillay, J.; Boers, L.S.; Algera, A.G.; Bos, L.D.J.; Dongelmans, D.A.; Hollmann, M.W.; Horn, J.; Vlaar, A.P.J.; et al. Ventilation management and clinical outcomes in invasively ventilated patients with COVID-19 (PRoVENT-COVID): A national, multicentre, observational cohort study. Lancet Respir. Med. 2021, 9, 139-148. [CrossRef]

17. Farcomeni, A.; Ventura, L. An overview of robust methods in medical research. Stat. Methods Med. Res. 2012, 21, 111-133. [CrossRef]

18. Grasselli, G.; Tonetti, T.; Protti, A.; Langer, T.; Girardis, M.; Bellani, G.; Laffey, J.; Carrafiello, G.; Carsana, L.; Rizzuto, C.; et al. Pathophysiology of COVID-19-associated acute respiratory distress syndrome: A multicentre prospective observational study. Lancet Respir. Med. 2020, 8, 1201-1208. [CrossRef]

19. ARDS Definition Task Force. Acute respiratory distress syndrome: The Berlin Definition. JAMA 2012, 307, 2526-2533.

20. Karagiannidis, C.; Windisch, W.; McAuley, D.F.; Welte, T.; Busse, R. Major differences in ICU admissions during the first and second COVID-19 wave in Germany. Lancet Respir. Med. 2021, 2600, 20-21.

21. Acute Respiratory Distress Syndrome Network. Ventilation with lower tidal volumes as compared with traditional tidal volumes for acute lung injury and the acute respiratory distress syndrome. N. Engl. J. Med. 2000, 342, 1301-1308. [CrossRef] [PubMed] 
22. Ranieri, V.M.; Eissa, N.T.; Corbeil, C.; Chassé, M.; Braidy, J.; Matar, N.; Milic-Emili, J. Effects of Positive End-expiratory Pressure on Alveolar Recruitment and Gas Exchange in Patients with the Adult Respiratory Distress Syndrome. Am. Rev. Respir. Dis. 1991, 144, 544-551. [CrossRef] [PubMed]

23. Fonarow, G.C.; Adams, K.F.; Abraham, W.T.; Yancy, C.W.; Boscardin, W.J. Risk Stratification for In-Hospital Mortality in Acutely Decompensated Heart Failure-Reply. JAMA 2005, 293, 2467. [CrossRef] [PubMed]

24. Dorey, A.; Tholance, Y.; Vighetto, A.; Perret-Liaudet, A.; Lachman, I.; Krolak-Salmon, P.; Wagner, U.; Struyfs, H.; de Deyn, P.P.; El-Moualij, B.; et al. Association of Cerebrospinal Fluid Prion Protein Levels and the Distinction Between Alzheimer Disease and Creutzfeldt-Jakob Disease. JAMA Neurol. 2015, 72, 267. [CrossRef]

25. Chan, A.-W.; Fung, K.; Tran, J.M.; Kitchen, J.; Austin, P.C.; Weinstock, M.A.; Rochon, P.A. Application of Recursive Partitioning to Derive and Validate a Claims-Based Algorithm for Identifying Keratinocyte Carcinoma (Nonmelanoma Skin Cancer). JAMA Dermatol. 2016, 152, 1122. [CrossRef] [PubMed]

26. Grasselli, G.; Zangrillo, A.; Zanella, A.; Antonelli, M.; Cabrini, L.; Castelli, A.; Cereda, D.; Coluccello, A.; Foti, G.; Fumagalli, R.; et al. Baseline Characteristics and Outcomes of 1591 Patients Infected with SARS-CoV-2 Admitted to ICUs of the Lombardy Region, Italy. JAMA-J. Am. Med. Assoc. 2020, 323, 1574-1581. [CrossRef]

27. Abate, S.M.; Checkol, Y.A.; Mantefardo, B. Global prevalence and determinants of mortality among patients with COVID-19: A systematic review and meta-analysis. Ann. Med. Surg. 2021, 64, 102204. [CrossRef]

28. Li, K.; Fang, Y.; Li, W.; Pan, C.; Qin, P.; Zhong, Y.; Liu, X.; Huang, M.; Liao, Y.; Li, S. CT image visual quantitative evaluation and clinical classification of coronavirus disease (COVID-19). Eur. Radiol. 2020, 30, 4407-4416. [CrossRef]

29. Fox, S.E.; Akmatbekov, A.; Harbert, J.L.; Li, G.; Brown, J.Q.; Heide, R.S.V. Pulmonary and cardiac pathology in African American patients with COVID-19: An autopsy series from New Orleans. Lancet Respir. Med. 2020, 8, 681-686. [CrossRef]

30. Carsana, L.; Sonzogni, A.; Nasr, A.; Rossi, R.S.; Pellegrinelli, A.; Zerbi, P.; Rech, R.; Colombo, R.; Antinori, S.; Corbellino, M.; et al. Pulmonary post-mortem findings in a series of COVID-19 cases from northern Italy: A two-centre descriptive study. Lancet Infect. Dis. 2020, 20, 1135-1140. [CrossRef]

31. Dolhnikoff, M.; Duarte-Neto, A.N.; Monteiro, R.A.d.; da Silva, L.F.F.; de Oliveira, E.P.; Saldiva, P.H.N.; Mauad, T.; Negri, E.M. Pathological evidence of pulmonary thrombotic phenomena in severe COVID-19. J. Thromb. Haemost. 2020, 18, 1517-1519. [CrossRef]

32. Berger, J.S.; Kunichoff, D.; Adhikari, S.; Ahuja, T.; Amoroso, N.; Aphinyanaphongs, Y.; Cao, M.; Goldenberg, R.; Hindenburg, A.; Horowitz, J.; et al. Prevalence and Outcomes of D-Dimer Elevation in Hospitalized Patients with COVID-19. Arterioscler. Thromb. Vasc. Biol. 2020, 40, 2539-2547. [CrossRef]

33. Short, S.A.P.; Gupta, S.; Brenner, S.K.; Hayek, S.S.; Srivastava, A.; Shaefi, S.; Singh, H.; Wu, B.; Bagchi, A.; Al-Samkari, H.; et al. D-dimer and Death in Critically Ill Patients with Coronavirus Disease 2019. Crit. Care Med. 2021, 49, e500-e511. [CrossRef]

34. Sole, F.D.; Farcomeni, A.; Loffredo, L.; Carnevale, R.; Menichelli, D.; Vicario, T.; Pignatelli, P.; Pastori, D. Features of severe COVID-19: A systematic review and meta-analysis. Eur. J. Clin. Investig. 2020, 50, e13378.

35. Yao, Y.; Cao, J.; Wang, Q.; Shi, Q.; Liu, K.; Luo, Z.; Chen, X.; Chen, S.; Yu, K.; Huang, Z.; et al. D-dimer as a biomarker for disease severity and mortality in COVID-19 patients: A case control study. J. Intensive Care 2020, 8, 49. [CrossRef] [PubMed]

36. Zhang, L.; Yan, X.; Fan, Q.; Liu, H.; Liu, X.; Liu, Z.; Zhang, Z. D-dimer levels on admission to predict in-hospital mortality in patients with Covid-19. J. Thromb. Haemost. 2020, 18, 1324-1329. [CrossRef] [PubMed]

37. Naymagon, L.; Zubizarreta, N.; Feld, J.; van Gerwen, M.; Alsen, M.; Thibaud, S.; Kessler, A.; Venugopal, S.; Makki, I.; Qin, Q.; et al. Admission D-dimer levels, D-dimer trends, and outcomes in COVID-19. Thromb. Res. 2020, 196, 99-105. [CrossRef]

38. COVID-ICU Group on behalf of the REVA Network and the COVID-ICU. Investigators. Clinical characteristics and day-90 outcomes of 4244 critically ill adults with COVID-19: A prospective cohort study. Intensive Care Med. 2021, 47, 60-73. [CrossRef]

39. Ferrando, C.; Suarez-Sipmann, F.; Mellado-Artigas, R.; Hernández, M.; Gea, A.; Arruti, E.; Aldecoa, C.; Martínez-Pallí, G.; Martínez-González, M.A.; Slutsky, A.S.; et al. Clinical features, ventilatory management, and outcome of ARDS caused by COVID-19 are similar to other causes of ARDS. Intensive Care Med. 2020, 2200-2211. [CrossRef] [PubMed]

40. Bartoletti, M.; Giannella, M.; Scudeller, L.; Tedeschi, S.; Rinaldi, M.; Bussini, L.; Fornaro, G.; Pascale, R.; Pancaldi, L.; Pasquini, Z.; et al. Development and validation of a prediction model for severe respiratory failure in hospitalized patients with SARS-CoV-2 infection: A multicentre cohort study (PREDI-CO study). Clin. Microbiol. Infect. 2020, 26, 1545-1553. [CrossRef]

41. Taj, S.; Kashif, A.; Fatima, S.A.; Imran, S.; Lone, A.; Ahmed, Q. Role of hematological parameters in the stratification of COVID-19 disease severity. Ann. Med. Surg. 2021, 62, 68-72. [CrossRef]

42. Kiss, S.; Gede, N.; Hegyi, P.; Németh, D.; Földi, M.; Dembrovszky, F.; Nagy, B.; Juhász, M.F.; Ocskay, K.; Zádori, N.; et al. Early changes in laboratory parameters are predictors of mortality and ICU admission in patients with COVID-19: A systematic review and meta-analysis. Med. Microbiol. Immunol. 2021, 210, 33-47. [CrossRef]

43. Idell, S.; Gonzalez, K.; Bradford, H.; MacArthur, C.K.; Fein, A.M.; Maunder, R.J.; Garcia, J.G.N.; Griffith, D.E.; Weiland, J.; Martin, T.R.; et al. Contribution of Tissue Factor Associated with Factor VII. Am. Rev. Respir. Dis. 1987, 136, 1466-1474. [CrossRef]

44. Sebag, S.C.; Bastarache, J.A.; Ware, L.B. Therapeutic Modulation of Coagulation and Fibrinolysis in Acute Lung Injury and the Acute Respiratory Distress Syndrome. Curr. Pharm. Biotechnol. 2011, 12, 1481-1496. [CrossRef]

45. Marin, M.; Orso, D.; Federici, N.; Vetrugno, L.; Bove, T. D-dimer specificity and clinical context: An old unlearned story. Crit. Care 2021, 25, 101. [CrossRef] 
46. Kutinsky, I.; Blakley, S.; Roche, V. Normal D-dimer levels in patients with pulmonary embolism. Arch. Intern. Med. 1999, 159, 1569-1572. [CrossRef]

47. Righini, M.; van Es, J.; den Exter, P.L.; Roy, P.; Verschuren, F.; Ghuysen, A.; Rutschmann, O.T.; Sanchez, O.; Jaffrelot, M.; Trinh-Duc, A.; et al. Age-adjusted D-dimer cutoff levels to rule out pulmonary embolism: The ADJUST-PE study. JAMA—J. Am. Med. Assoc. 2014, 311, 1117-1124. [CrossRef] [PubMed] 